\title{
Self-esteem and intentions mediate perceived fitness with physical activity in Finnish adolescents with long-term illness or disabilities
}

\author{
Kwok Ng*, Raili Välimaa, Pauli Rintala, Jorma Tynjälä, Jari Villberg, and Lasse Kannas \\ Faculty of Sport and Health Sciences, University of Jyväskylä, Jyväskylä, Finland
}

Copyright: (C) $2014 \mathrm{~K}$. Ng et al. This is an open access article licensed under the Creative Commons Attribution License (http://creativecommons.org/licenses/by/4.0/).

\begin{abstract}
Background: The International Classification of Functioning, Disability and Health (ICF) is recognised as the common language in disability research. However, personal factors in the ICF are not explicitly coded because of cultural differences that influence physical activity (PA) participation. The ICF suggests using fitness as a personal factor, as well as other psychological assets. Intentions may serve as such psychological assets and studies on the antecedents to intentions which prompts PA behaviours is lacking in adolescent long term illness or disability (LTID) populations. Objective: The purpose of this study was to report how ICF personal factors can influence participation in PA. Perceived fitness (FIT), global self-esteem (GSE), and PA intentions (INT) are hypothesised to positively predict PA behaviours among adolescents with LTID after controlling for age. Methods: The data from Finnish 13 and 15 years old adolescents from the self-reported Health Behaviour in School-aged Children study from 2002 and 2010 were pooled. Those with LTID as stated by a medical doctor were included $(N=1,059)$. Serial mediation with ordinary least squares path analysis was used. Boys and girls were separately analysed, FIT was the independent variable, GSE and INT as mediators, and age controlled moderate-to-vigorous PA (MVPA) the dependent variable. Bias-corrected bootstrap confidence intervals were used to test for significance of the direct and indirect paths. Results: FIT was positively related to GSE and INT for boys and girls. Furthermore, INT were positively related to MVPA for boys and girls. These relationships were statistically significant. Therefore, INT can be seen to mediate the relationship between FIT and MVPA after controlling for age. GSE also acted as a statistically significant mediator for boys, between FIT and INT. Therefore serial mediation was presented with boy's MVPA, whereas in the girl's model, only INT mediated FIT and MVPA. Conclusions: Personal factors influence PA participation in adolescents with LTID. Support for increasing self-esteem for boys seems to be important and it should be taken into account when different PA promotion strategies are planned for boys. Differences in PA between genders suggest overall more promotion of PA for girls is still needed.
\end{abstract}

Keywords: perceived fitness, self-esteem, intentions, MVPA, HBSC, adapted physical activity

\section{Introduction}

Physically active lifestyle is important for adolescents with long term illnesses, disabilities or medical conditions (LTID), however studies including adolescents with LTID have reported lower amounts of physical activity (PA) (Lieberman \& McHugh, 2001; Ng, Rintala, Tynjälä, Villberg, \& Kannas, 2014; Rimmer, Rowland, \& Yamaki, 2007) or no different amounts of PA (Rintala et al., 2011; van Gent et al., 2007) to adolescents without LTID. The inconsistent results have been attributed to a number of methodological reasons,

\footnotetext{
* Address for correspondence: Kwok Ng, Department of Sport Sciences, PO Box 35, 40014 University of Jyväskylä, Jyväskylä, Finland. E-mail: kwok.ng@jyu.fi
}

hence large sample representative data, as in this study, can be used to minimise these reporting errors.

In this paper, the World Health Organisation's International Classification of Functioning, Disability and Health (ICF, see World Health Organization, 2001) was used as a framework to guide the analysis to explain PA participation. The ICF has been widely recognised as the common language for disability and functioning (Bickenbach, 2012), and can be applied to PA (Rimmer, 2006). The ICF is divided into two parts that interact with each other to help classify a person's situation in terms of functional health. The first part is related to the functioning and disability and has two components as identified by 1) body functions and structures, and 2) activities and participation, while the second part is related to contextual factors and have 
also two components as identified by 1) environmental factors, and 2) personal factors (more information: http://www.who.int/classifications/icf/en/).

Given that adolescents with LTID have impairments affecting their functioning, much research in adapted physical activity has paid attention to the external environmental component of the ICF (e.g., family, peers, infrastructure, attitudes, etc.), while less is studied about internal personal factors (Adolfsson, 2011). Furthermore, personal factors are not coded in the ICF, rather it is suggested that they are components that:

....are the particular background of an individual's life and living, and comprise features of the individual that are not part of a health condition or health status. These factors may include gender, race, age, other health conditions, fitness ...individual psychological assets and other characteristics, all or any of which may play a role in disability at any level. (WHO, 2001, p. 17)

Part of the reasoning for a lack of coding of personal factors in the ICF is due to the complexity of how these factors may interact and differ between cultures (World Health Organization, 2010), which has prompted researchers to attempt to gain a better understanding of personal factors in its relation to functional health and disability (Bickenbach, 2012).

Fitness (FIT) is explicitly listed as an example of ICF personal factors (World Health Organization, 2001). FIT has been studied as actual and perceived fitness, with correlations showing similarities (Huotari, Sääkslahti, \& Watt, 2009). Global self-esteem (GSE) is multidimensional and consists of evaluations of one's value as a person (Fox, 1988). It is often reported that adolescents with LTID have lower levels of GSE than their peers without LTID (Shields, Murdoch, Loy, Dodd, \& Taylor, 2006). Several studies have also reported a causal relationship whereby increasing FIT can increase GSE, whereas no differences in FIT were reported with increases of GSE (Sonstroem, 1997; Spence, McGannon, \& Poon, 2005). Studies that have looked at specific populations with reported lowered GSE have shown that an increase in GSE was achieved from increased PA participation (DeBate, Gabriel, Zwald, Huberty, \& Zhang, 2009). Based on these assumptions, we investigate if self-esteem becomes a mediator of the relationship between fitness and PA participation.

One of the most used theories investigating the relationship between intentions (INT) and behaviours is the theory of planned behaviour (Ajzen, 1985; Ajzen, 1991). INT are drawn from three constructs; attitudes; subjective norms; and, perceived behavioural control (PBC). Of these three constructs, the relationship between PBC and INT does not change with age (Chatzisarantis, Hagger, Kawabata, \& Kamarova, 2014). Furthermore, reviews have also demonstrated that PBC also, although slightly weaker than INT, influences PA behaviour directly (Hagger, 2014; McEachan, Conner, Taylor, \& Lawton, 2011). PBC is a combination of perceived controlling of factors needed for PA and its level of importance (Ajzen, 1985). As previously noted (Huotari et al., 2009), self-perceived fitness is strongly correlated to actual fitness levels, indicating the principle of control, and fitness is a major factor in doing physical activities, indicating the principle of importance, thus together, is considered here as PBC.

The aim of this study was to examine how personal factors can be used to predict PA participation. It was done by investigating the relationship between perceived fitness and PA participation. Furthermore, three other possible relationships were investigated 1) global self-esteem (GSE) mediating the relationship between FIT and age controlled moderate-to-vigorous PA (MVPA), 2) INT mediating the relationship between FIT and MVPA, and 3) GSE and INT mediating in a serial manner the relationship between FIT and MVPA. Age was included to control for PA participation as older adolescents reported fewer days of MVPA (Currie et al., 2012) and gender was stratified as there are noticeable differences with reported PA participation of adolescents with LTID (Ng et al., 2014).

\section{Methods}

\section{Participants}

The data consisted of 1,059 students $(56.3 \%$ girls, mean age $=14.76$ years, $S D=1.06$ ), from a nationally representative sample of Finnish school children who participated in the Health Behaviour in School-aged Children (HBSC) study in 2002 and 2010. Classes in schools were selected by stratified sampling around Finland. The pupils in school voluntarily took part in the study and completed a paper questionnaire in a classroom. Instructions were given to the teachers who administered the completion of questionnaires. When completed, the papers were placed into an envelope immediately and due to the anonymous nature of data collection, it was not possible to identify the pupil that completed the survey. The ethics of the study was approved by the Finnish Teachers' Union and the Finnish National Board of Education. Specific details about the data collection can be found on the HBSC 
questionnaire protocol ${ }^{1}$. Adolescents that reported they have been told by a doctor that they have a LTID were included in the sample. In addition, within this study design, only adolescents whose body mass index was within the range of 15 and 40 were included. This was to eliminate analysis of adolescents with extreme under or over weight based on international recommendations (Cole, Bellizzi, Flegal, \& Dietz, 2000).

\section{Measures}

Measures of perceived fitness (FIT) were generated from a single item, taken from the Finnish HBSC questionnaire, "How fit do you think you are?", responses were "not fit at all" (1), "moderately fit" (2), "fit" (3), "very fit" (4). Global self-esteem (GSE) was derived from a composite score of Rosenberg's self-esteem scale (Rosenberg, 1965). Higher composite scores indicate higher levels of self-esteem. Intentions for PA (INT) were measured using a single item on the individual's intention to be physically active when the respondent is 20 years old with a four point scale response ranging from "definitely no" (1) to "definitely yes" (4). Moderate-to-vigorous Physical Activity (MVPA) was based on a self-report item on the amount of days whereby the individual was moderately to vigorously physically active for 60 minutes or more (Sallis \& Patrick, 1994). Examples of the types of activities were included within

${ }^{1}$ The HBSC protocol consists of documentation of data collection, sampling, data checking, and sharing of data and can be accessed from the HBSC website (www.hbsc.org). the question to help the pupils to quantify their PA and sport participation. This item has been validated in the Finnish language (Vuori et al., 2005).

\section{Data analysis}

Studied variables were compared with $t$-test statistic to reveal any statistical significant differences at .05 or less. Ordinary least squares regression analysis was used to demonstrate how personal factors explain age controlled MVPA participation. Bias-corrected bootstrap confidence intervals were used to test for significance of the direct and indirect paths. The same regression analysis was repeated for both genders. Full serial mediation model with: a (FIT-GSE/INT), b (GSE/INT-MVPA), c (FIT-MVPA), and d (GSE-INT) regression coefficients is in Figure 1. In order to put mediators in serial for the association between independent and dependent variables, certain conditions must be met for serial mediation macro for SPSS [PROCESS model 6 (Hayes, 2013)] to work. First there must be a substantial relation between an independent variable and the mediating variable, and there must be a relation between the mediating variable and the dependent variable when accounting for the independent variable. The correlations between the variables are presented in Table 1.

Secondly, by definition, "mediation requires a causal precedence, such that the independent variable precedes and is a cause of the mediator, and the mediator must precede and be a cause of the dependent

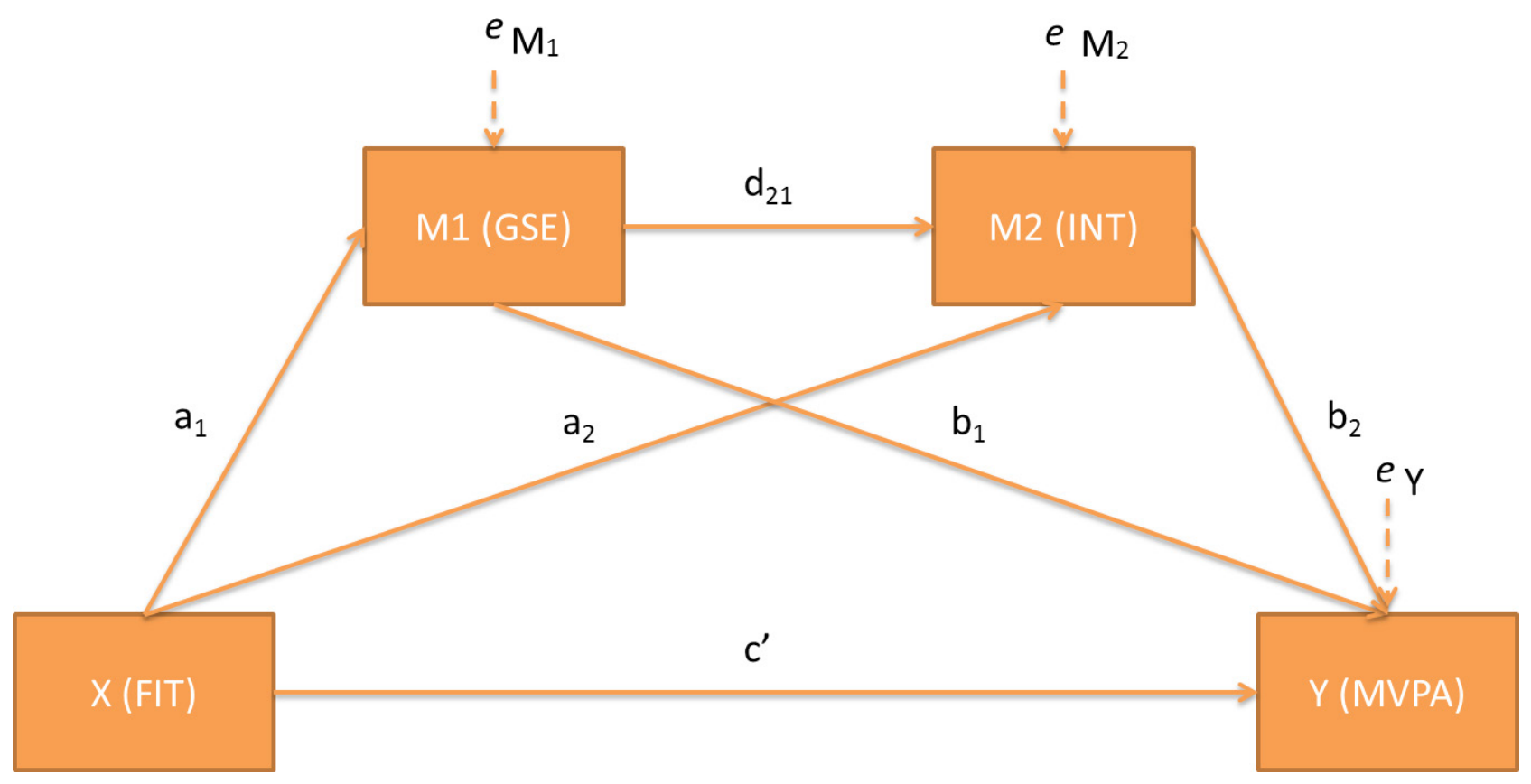

Figure 1. Statistical diagram of serial mediation of 2 mediators: M1 (GSE = global self-esteem) and M2 (INT = physical activity intentions); between X (FIT = perceived fitness) and Y (MVPA = moderate-to-vigorous physical activity) 
Table 1

Variable means, standard deviations, and Spearman correlations $(N=1,059)$

\begin{tabular}{lccccc}
\hline & & & \multicolumn{3}{c}{ Correlation coefficient } \\
\cline { 5 - 6 } & Mean & SD & 1 & 2 & 3 \\
\hline 1. Perceived fitness & & & & & \\
$\quad$ Overall & 2.72 & 0.73 & - & & \\
Boy & 2.80 & 0.77 & - & & \\
Girl & 2.67 & 0.70 & - & & \\
2. Global self-esteem & & & & & \\
Overall & 24.53 & 4.83 & $.351^{* *}$ & - & \\
Boy & 26.03 & 4.29 & $.336^{* *}$ & - & \\
Girl & 23.40 & 4.91 & $.344^{* *}$ & - & - \\
3. PA intentions & & & & & \\
$\quad$ Overall & 3.44 & 0.63 & $.376^{* *}$ & $.184^{* *}$ & - \\
Boy & 3.41 & 0.68 & $.399^{* *}$ & $.247^{* *}$ & - \\
Girl & 3.46 & 0.60 & $.365^{* *}$ & $.171^{* *}$ & - \\
4. Moderate-to-vigorous PA & & & & & \\
$\quad$ Overall & 3.93 & 2.01 & $.455^{* *}$ & $.189^{* *}$ & $.344^{* *}$ \\
Boy & 4.17 & 2.08 & $.465^{* *}$ & $.214^{* *}$ & $.397^{* *}$ \\
Girl & 3.75 & 1.94 & $.436^{* *}$ & $.137^{* *}$ & $.307^{* *}$ \\
\hline
\end{tabular}

$* * p \leq .01$, two-tailed.

variable" (MacKinnon \& Luecken, 2008). As the data was collected from a cross-sectional study, two widely used theories were utilised to provide causal assumptions. Within the hierarchy model of self-esteem, perceived fitness was a component of global self-esteem (Fox, 1988; Haugen, Ommundsen, \& Seiler, 2013). Furthermore, within the framework of the theory of planned behaviour (Ajzen, 1991), perceived fitness was treated as a component of $\mathrm{PBC}$, and that is seen as a direct and indirect predictor of behaviour (Hagger, 2014).

\section{Results}

In this study, there were slightly more girls $(n=596$, mean age $=14.77, S D=1.05)$ than boys $(n=463$, mean age $=14.76, S D=1.06$ ) with LTID. Boys reported more days in the last 7 days of 60 minutes of MPVA (mean $=4.17$ days, $S D=2.08$ ) than girls, who reported considerably less (mean $=3.75$ days, $S D=1.94)$ with these differences statistically significant $(t=3.39$, $p=.001$ ). More boys reported as being "fit", as their fitness scores were higher $($ mean $=2.80, S D=0.77$ ) than girls (mean $=2.67, S D=0.70)$, and these differences were statistically significant $(t=2.977, p=.003$ ). Higher levels of self-esteem, as indicated by higher self-esteem scores, were reported by boys (mean $=26.3$, $S D=4.29)$ than girls (mean $=23.4, S D=4.91)$, and these differences were statistically significant $(t=8.93$, $p<.001)$. More girls indicated that they would definitely do PA in the future than boys, but the differences were not statistically significant. Spearman's correlation coefficients between the dependent variable, moderate-to-vigorous PA (MVPA), and the independent variable perceived fitness (FIT) were $.455, .465$, and .436 for overall, boys, and girls, respectively (Table 1) showing sufficient relationships between these variables for linear regression analysis.

In the regression analysis, the regression values were reported with their significance, and total model effects reported using confidence intervals in Table 2. Perceived fitness (FIT) was positively related to global self-esteem (GSE) $\left(a_{1}\right)$ and PA intentions (INT) $\left(a_{2}\right)$ for boys $\left(\mathrm{a}_{1}=1.93, p<.001 ; \mathrm{a}_{2}=0.30, p<.001\right)$ and girls $\left(a_{1}=2.42, p .001 ; a_{2}=0.29, p<.001\right)$. Furthermore, INT was positively related to MVPA for boys $\left(\mathrm{b}_{2}=0.81\right.$, $p<.001)$ and girls $\left(\mathrm{b}_{2}=0.58, p<.001\right)$. Therefore, INT can be seen to mediate the relationship between FIT and MVPA after controlling for age.

There was no direct relationship between GSE and MVPA $\left(b_{1}\right)$ for both boys and girls. However, when GSE was included in the model, the total effect was significant $(c=1.17, p<.001)$ based on 10,000 bootstrap 
Table 2

Direct, indirect, and total effects (and 95\% confidence intervals) of moderate-to-vigorous physical activity on perceived fitness, global self-esteem, and physical activity intentions

\begin{tabular}{|c|c|c|c|c|c|c|}
\hline & \multicolumn{6}{|c|}{ MVPA } \\
\hline & Direct & $95 \% \mathrm{CI}$ & Indirect & $95 \% \mathrm{CI}$ & Total & $95 \% \mathrm{CI}$ \\
\hline \multicolumn{7}{|c|}{ Overall $\left(R^{2}=.225\right)$} \\
\hline FIT-GSE & 2.34 & {$[1.94,2.74]$} & 0.030 & {$[-0.026,0.088]$} & & \\
\hline FIT-INT & 0.298 & {$[0.241,0.355]$} & 0.201 & {$[0.139,0.277]$} & & \\
\hline GSE-INT & 0.008 & {$[-0.001,0.017]$} & 0.013 & {$[-0.001,0.028]$} & & \\
\hline FIT & 0.987 & {$[0.817,1.16]$} & & & 1.23 & {$[1.088,1.373]$} \\
\hline \multicolumn{7}{|c|}{$\operatorname{Boy}\left(R^{2}=.246\right)$} \\
\hline FIT-GSE & 1.93 & {$[1.37,2.48]$} & 0.043 & {$[-0.038,0.131]$} & & \\
\hline FIT-INT & 0.30 & {$[0.209,0.392]$} & 0.243 & {$[0.138,0.391]$} & & \\
\hline GSE-INT & 0.02 & {$[0.001,0.37]$} & 0.032 & {$[0.009,0.069]$} & & \\
\hline FIT & 0.952 & {$[0.700,1.20]$} & & & 1.27 & {$[1.056,1.485]$} \\
\hline \multicolumn{7}{|c|}{$\operatorname{Girl}\left(R^{2}=.201\right)$} \\
\hline FIT-GSE & 2.42 & {$[1.86,2.97]$} & -0.016 & {$[-0.090,0.054]$} & & \\
\hline FIT-INT & 0.294 & {$[0.225,0.362]$} & 0.171 & {$[0.096,0.261]$} & & \\
\hline GSE-INT & 0.006 & {$[-0.004,0.017]$} & 0.009 & {$[-0.005,0.028]$} & & \\
\hline FIT & 1.10 & {$[0.774,1.24]$} & & & 1.17 & {$[0.973,1.367]$} \\
\hline
\end{tabular}

Note. $\quad$ MVPA = moderate-to-vigorous physical activity, $\mathrm{CI}=$ confidence interval. FIT = perceived fitness, GSE = global self-esteem, INT = physical activity intentions. Confidence intervals not including zero are in boldface.

samples was entirely above zero (0.97 to 1.36 ). GSE also acted as a mediator for boys, between FIT and INT $\left(\mathrm{d}_{21}=0.02, p=.017\right)$. As such, serial mediation was presented with boy's MVPA, with a significant total effect $(\mathrm{c}=1.27, p<.001)$ based on 10,000 bootstrap samples was entirely above zero (1.06 to 1.48 ). Those paths added further to the direct effect between FIT and MVPA ( $\mathrm{c}^{\prime}=0.95, p<.001$ ) for boys (Figure 2 ).

\section{Discussion}

This study has, through serial mediation modelling, shown that global self-esteem (GSE) can be a mediator of the relationship between perceived fitness (FIT) and physical activity intentions (INT) in boys but not in girls with long term illnesses or disabilities (LTID). As such, for boys, a change in physical activity participation is predicted by changes in intentions for physical activity, which was influenced by slight changes in global self-esteem, which was subsequently influenced by perceived fitness. For girls, PA was significantly predicted only by INT and FIT.

This study also showed that the overall amounts of PA reported by this sample were significantly lower than the Nordic region average of 4.3 days of MVPA (Iannotti et al., 2009). Due to the positive regression coefficients, we would encourage further studies to extend the relationships between these personal factors and meeting MVPA recommendations for daily participation for adolescents with LTID.

\section{Personal factors}

There are no codes for personal factors within the ICF, yet it is still included into the ICF framework, and some guidance is available by looking at some examples in its definition (World Health Organization, 2001). We looked at these examples and tried to minimise the number of ICF personal factors to perceived fitness (FIT), global self-esteem (GSE), and intentions for PA (INT) with the purpose of demonstrating precursors to PA participation.

Results have shown the importance of FIT in PA participation and GSE are quite established in general population studies (Inchley, Kirby, \& Currie, 2011). Even in our sample, with lower levels of PA participation in comparison to the Finnish average, high levels of FIT were directly related to PA participation and GSE in both boys and girls. These findings reinforce utilizing fitness (Rimmer, 2006) and GSE (Shields et al., 2006) as personal factors when attempting to increase PA participation.

The theory of planned behaviour (Ajzen, 1991) fitted well to the data. FIT functioned as a component 

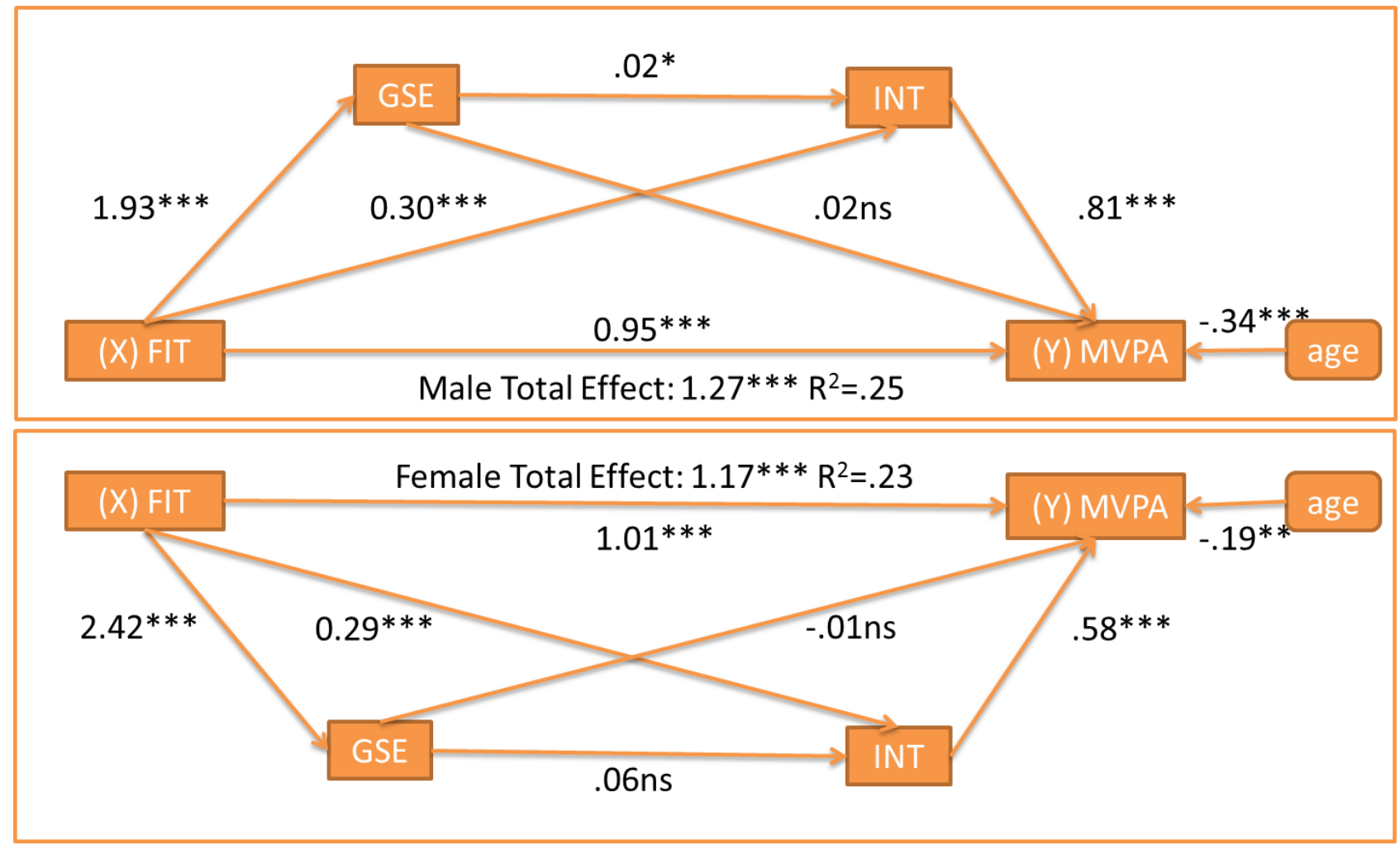

Figure 2. Regression correlations of direct and total effects of 2 mediators: GSE (global self-esteem) and INT (physical activity intentions); between X (perceived fitness) and age controlled Y (MVPA - moderate-to-vigorous physical activity) for boys and girls. ${ }^{*} \mathrm{p}<.05 ;{ }^{* *} \mathrm{p}<.01 ;{ }^{* *} \mathrm{p}<.001$.

of perceived behavioural control (PBC) for PA (Ajzen, 1985; Huotari et al., 2009). The results for both boys and girls showed that high level of FIT as PBC was related to high amounts of PA participation, and high levels of INT. It also revealed that INT acted as a mediator between FIT and PA participation. The strength of the changes in levels of FIT when directly influencing PA participation was more than INT, which can be interpreted that FIT was perceived as actual and real barriers towards PA participation (Chatzisarantis et al., 2014).

Our results also demonstrated that GSE is related to INT only for boys with LTID. This is quite an interesting finding, since much literature on the relationship between GSE and PA often reports higher sensitivity for GSE (in relation to PA participation) in girls (Biddle \& Asare, 2011). These results have been explained by the findings that adolescent girls have generally lower levels of GSE as they age between 13 and 15 years old, whereas in adolescent boys, GSE tends to increase (Inchley et al., 2011). Girls also participate in lower amounts of PA than boys (Whitehead \& Biddle, 2008). Even though FIT is related to GSE (Spence et al., 2005), other components in GSE may be more important for girls, for example, cognitive selfesteem (Fox, 1988), and therefore GSE was not seen to be a significant predictor for PA intentions. There were further perspectives on self-esteem of girls investigated by Kololo, Guszkowska, Mazur, and Dzielska (2012). In their study, girls who reported dissatisfaction with body appearance were suggested that these feelings can be symptomatic of a serious disorder that causes lowered GSE. The authors also reported that almost three-quarters of their sample population felt that, even though they had average appearances, they still participated in insufficient amounts of PA (Kololo et al., 2012). It was suggested that further incentives are needed to promote more PA participation. It is with this notion that provides an insight into how the relationship between GSE and INT is significant for adolescent boys.

For young boys, incentives to be physically active are more present than for girls. Being in the mainstream education system, both boy and girl adolescents with LTID are prone to be abnormal due to blemishes, while self-perceived "felt" stigmatization is more prominent than "enacted" stigma (Scambler, 2012). Furthermore, studies have also shown that adolescents with LTID experience more physicality such as bullying than their peers without LTID (Sentenac et al., 2012).The details of the incentives to be physically active can be considered as follows. The socially constructed world 
that defines ability over disability is slow to recognise that everyone has the capability to be classified within the ICF (Bickenbach, 2012), and it could be this that prompts this inner feeling of self-esteem when being able to do more physical tasks. An example of this is, for some adolescents with breathing difficulties such as asthma, the physical barriers to conduct moderateto-vigorous physical activities for extended periods of time. Yet there are studies that also reported no differences in PA levels between those with and without asthma (van Gent et al., 2007). An increase in selfesteem is likely for those who do the same amounts of PA as their peers without asthmatic symptoms.

\section{Limitations}

Self-reported questionnaires were used to collect data. The question of LTID did not include measures of severity so a wide spectrum of individuals have been included in the study and pooled together. Caution is advised when generalising these results to a disability representative group since the data was collected from mainstream education and does not include special schools. Furthermore, the variables that were used in the study were also collected using self-report questionnaires and mainly single items (with the exception of self-esteem). While studies have shown similar perceived fitness levels to observed fitness indexes of 14 year old Finnish pupils (Huotari et al., 2009), there can be some over reporting of this measure. Other studies have also demonstrated acceptable validity in the MVPA measure (Vuori et al., 2005), although some research has indicated an under reporting (Ridgers, Salmon, Parrish, Stanley, \& Okely, 2012) which could have narrowed the regression coefficients. Finally, the intention variable is set in the future, and its strength to mediate a reported behaviour at the time of the data collection may require further analysis. For the time being, the item relates to the intention to be physically active 5-7 years in the future. A longitudinal study might be a feasible way to provide an accurate picture of how well this variable mediates the behaviour by reassessing PA participation in follow up studies.

\section{Conclusions}

Overall, the findings have shown that perceived fitness, self-esteem, intentions, and gender can be regarded as significant personal factors associated with participation in PA. These personal factors are seen as important and related to one another. In accordance with the ICF, personal factors are not explicitly coded, and this leaves researchers with much work to deliver coherence when discussing personal factors. Further development of questionnaires that includes severity of LTID would provide some specific results needed to refine the ICF, as well as repeated studies across different countries to ensure consistency within personal factors.

\section{References}

Adolfsson, M. (2011). Applying the ICF-CY to identify everyday life situations of children and youth with disabilities (Unpublished doctoral dissertation). Swedish Institute for Disability Research, Jönköping.

Ajzen, I. (1985). From intentions to actions: A theory of planned behavior. In J. Kuhl \& J. Beckmann (Eds.), Action-control: From cognition to behavior (pp. 11-39). Heidelberg: Springer.

Ajzen, I. (1991). The theory of planned behavior. Organizational Behavior and Human Decision Processes, 50, 179-211. doi:10.1016/0749-5978(91)90020-T

Bickenbach, J. E. (2012). The international classification of functioning, disability and health and its relationship to disability studies. In N. Watson, A. Roulstone, \& C. Thomas (Eds.), Routledge handbook of disability studies (pp. 51-66). Abingdon, Oxon: Routledge.

Biddle, S. J. H., \& Asare, M. (2011). Physical activity and mental health in children and adolescents: A review of reviews. British Journal of Sports Medicine, 45, 886-895.

Chatzisarantis, N. L. D., Hagger, M. S., Kawabata, M., \& Kamarova, S. (2014). Adherence to physical activity. In A. G. Papaioannou \& D. Hackfort (Eds.), Routledge companion to sport and exercise psychology: Global perspectives and fundamental concepts (pp. 771-784). Hove: Routledge.

Cole, T. J., Bellizzi, M. C., Flegal, K. M., \& Dietz, W. H. (2000). Establishing a standard definition for child overweight and obesity worldwide: International survey. BMJ, $320,1240$.

Currie, C., Zanotti, C., Morgan, A., Currie, D., de Looze, M. E., Roberts, C., ... Barnekow, V. (2012). Social determinants of health and well-being among young people. Health Behaviour in School-aged Children (HBSC) study: International report from the 2009/2010 survey (No. Health Policy for Children and Adolescents, No. 6). Copenhagen, Denmark: WHO Regional Office for Europe.

DeBate, R. D., Gabriel, K. P., Zwald, M., Huberty, J., \& Zhang, Y. (2009). Changes in psychosocial factors and physical activity frequency among third to eighth-grade girls who participated in a developmentally focused youth sport program: A preliminary study. Journal of School Health, 79, 474-484.

Fox, K. R. (1988). The self-esteem complex and youth fitness. Quest, 40, 230-246.

Hagger, M. S. (2014). The trans-contextual model of motivation: An integrated multi-theory model to explain the processes of motivational transfer across context (Doctoral dissertation). University of Jyväskylä. Studies in Sport, Physical Education and Health, 203.

Haugen, T., Ommundsen, Y., \& Seiler, S. (2013). The relationship between physical activity and physical self-esteem in adolescents: The role of physical fitness indices. Pediatric Exercise Science, 25, 138-153. 
Hayes, A. F. (2013). Introduction to mediation, moderation, and conditional process analysis: A regression-based approach. New York, NY: The Guildford Press.

Huotari, P., Sääkslahti, A., \& Watt, A. (2009). Associations between the self-estimated and actual physical fitness scores of Finnish grade 6 students. Physical Education and Sport, 7, 27-36.

Iannotti, R. J., Janssen, I., Jaug, E., Kololo, H., Annaheim, B., \& Borraccino, A. (2009). Interrelationship of adolescent physical activity, screen-based sedentary behaviour, and social and psychological health. International Journal of Public Health, 54, 191-198.

Inchley, J., Kirby, J., \& Currie, C. (2011). Longitudinal changes in physical self-perceptions and associations with physical activity during adolescence. Pediatric Exercise Science, 23, 237-249.

Kololo, H., Guszkowska, M., Mazur, J., \& Dzielska, A. (2012). Self-efficacy, self-esteem and body image as psychological determinants of 15 year old adolescents' physical activity levels. Human Movement, 13, 264-270.

Lieberman, L. J., \& McHugh, E. (2001). Health-related fitness of children who are visually impaired. Journal of Visual Impairment and Blindness, 95, 272-287.

MacKinnon, D. P., \& Luecken, L. J. (2008). How and for whom? Mediation and moderation in health psychology. Health Psychology, 27(Suppl. 2), S99-S100. doi:10.1037/0278-6133.27.2(Suppl.).S99

McEachan, R. R. C., Conner, M., Taylor, N. J., \& Lawton, R. J. (2011). Prospective prediction of health-related behaviours with the theory of planned behaviour: A metaanalysis. Health Psychology Review, 5, 97-144. doi:10.1080 /17437199.2010.521684

Ng, K. W., Rintala, P., Tynjälä, J. A., Villberg, J., \& Kannas, L. K. (2014). Physical activity patterns of adolescents with long term illnesses or disabilities in Finnish general education. European Journal of Adapted Physical Activity, 7, 58-72.

Ridgers, N. D., Salmon, J., Parrish, A., Stanley, R. M., \& Okely, A. D. (2012). Physical activity during school recess: A systematic review. American Journal of Preventive Medicine, 43, 320-328. doi:10.1016/j.amepre.2012.05.019

Rimmer, J. H. (2006). Use of the ICF in identifying factors that impact participation in physical activity/rehabilitation among people with disabilities. Disability and Rehabilitation, 28, 1087-1095.

Rimmer, J. H., Rowland, J. L., \& Yamaki, K. (2007). Obesity and secondary conditions in adolescents with disabilities: Addressing the needs of an underserved population. Journal of Adolescent Health, 41, 224-229. doi:10.1016/j. jadohealth.2007.05.005
Rintala, P., Välimaa, R. S., Tynjälä, J. A., Boyce, W. F., King, M., Villberg, J., \& Kannas, L. K. (2011). Physical activity of children with and without long-term illness or disability. Journal of Physical Activity \& Health, 8, 1066-1073.

Rosenberg, M. (1965). Society and the adolescent self-image. Princeton, NJ: Princeton University Press.

Sallis, J. F., \& Patrick, K. (1994). Physical activity guidelines for adolescents: Consensus statement. Pediatric Exercise Science, 6, 302-314.

Scambler, S. (2012). Long-term disabling conditions and disability theory. In N. Watson, A. Roulstone, \& C. Thomas (Eds.), Routledge handbook of disability studies (pp. 136150). Abingdon: Routledge.

Sentenac, M., Gavin, A., Gabhainn, S. N., Molcho, M., Due, P., Ravens-Sieberer, U., ... Godeau, E. (2012). Peer victimization and subjective health among students reporting disability or chronic illness in 11 western countries. European Journal of Public Health, 22, 1-6. doi:0.1093/ eurpub/cks073

Shields, N., Murdoch, A., Loy, Y., Dodd, K. J., \& Taylor, N. F. (2006). A systematic review of the self-concept of children with cerebral palsy compared with children without disability. Developmental Medicine and Child Neurology, 48, 151-157.

Sonstroem, R. J. (1997). Physical activity and self-esteem. In W. P. Morgan (Ed.), Physical activity and mental health (pp. 127-144). London: Taylor and Francis.

Spence, J. C., McGannon, K. R., \& Poon, P. (2005). The effect of exercise on global self-esteem: A quantitative review. Journal of Sport and Exercise Psychology, 27, 311.

van Gent, R., van der Ent, C. K., van Essen-Zandvliet, L. E. M., Rovers, M. M., Kimpen, J. L. L., de Meer, G., \& Klijn, P. H. C. (2007). No differences in physical activity in (un) diagnosed asthma and healthy controls. Pediatric Pulmonology, 42, 1018-1023. doi:10.1002/ppul.20672

Vuori, M. T., Ojala, S. A. K., Tynjälä, J. A., Villberg, J., Välimaa, R. S., \& Kannas, L. K. (2005). Liikunta-aktiivisuutta koskevien kysymysten stabiliteetti WHO-koululaistutkimuksessa [The stability of questions concerning physical activity in the HBSC study]. Liikunta \& Tiede, 42(6), $39-46$.

Whitehead, S., \& Biddle, S. J. H. (2008). Adolescent girls' perceptions of physical activity: A focus group study. European Physical Education Review, 14, 243-262. doi:10.1177/1356336X08090708

World Health Organization. (2001). International classification of functioning, disability and health (ICF). Geneva, Switzerland: Author.

World Health Organization. (2010). The ICF: An overview. Retrieved from http://www.cdc.gov/nchs/data/icd9/ICFoverview_FINALforWHO10Sept.pdf 